\title{
Pelaksanaan Kegiatan Pengabdian Masyarakat di Komplek Perumahan PT.BDSN Desa Tangga Batu 1 kec. Parmaksian Kab. Toba, Ramadhan 1442 H, 2021 M
}

\author{
Suhendri M.Sos, Zaika Evans Prayoga, Angga Al Fajari \\ M. Raihan Fahmi, Mushlih Shabir Hamzah, Haris Munandar. \\ Sekolah Tinggi Agama Islam As-sunnah, Indonesia
}

Email:suhenddria@gmail.com

\begin{abstract}
In this day and age the adherents of Islam are very many, ranging from children to adults, but many are only Muslim but do not know anything about Islam, both the basics and others. Likewise in the country of Indonesia, there are many people who do not understand the basics of Islam, especially in the Toba area which is mostly Christian. Because it is really needed people who can teach the true religion of Islam well there who can help people understand Islam properly. From the above statement, a question can be drawn how to solve the problem of a lack of understanding of the correct Islam in areas with Islamic minorities? Therefore, we are conducting Field Work Lectures in the Toba area to overcome this problem, which is expected to produce satisfactory results and can help in the development of Islam in Indonesia
\end{abstract}

.Keyword: Basic of Islam, minorities, Islam

\section{ملخص}

في هذا اليوم وهذا العصر ، يتعدد أتباع الإسلام ، من الأطفال إلى الكبار ، لكن الكثير

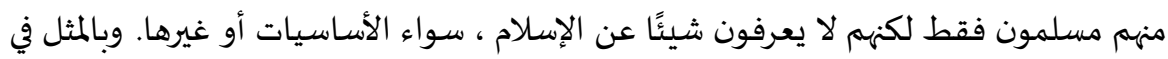

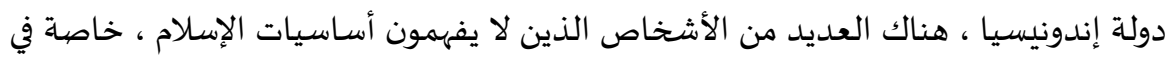

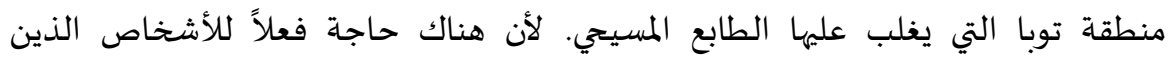

يستطيعون تعليم الدين الحقيقي للإسلام جيدًا والذين يمكنهم مساعدة الناس على فهان فهم

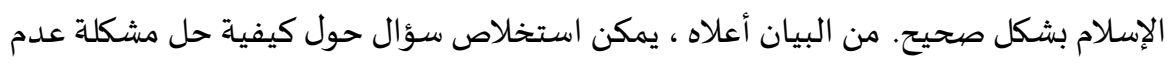

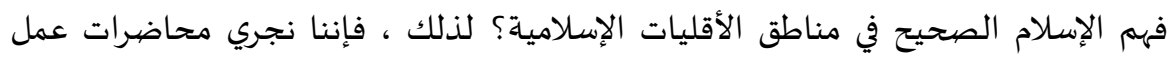

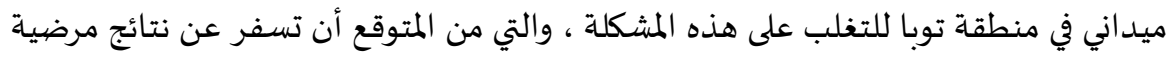

ويمكن أن تساعد في تطوير الإسلام في إندونيسيا.

الكلمات الرئيسية : أساسيات الإسلام ، الأقليات ، الإسلام 


\section{Pendahuluan}

Komplek Perumahan PT BDSN Simangkuk Desa Tangga Batu 1 Kec. Parmaksian Kab. Toba adalah suatu komplek yang berada di daerah dataran tinggi, dihuni oleh pekerja pekerja perusahaan yang berasal dari daerah jawa dan mayoritas penduduknya beragama islam.

Di dalam ingkungan Komplek Perumahan PT.BDSN Simagkuk Desa Tangga Batu 1 Kec. Parmaksian Kab. Toba terdapat satu masjid yang mana menjadi pusat peribadatan umat islam di dalam komplek tersebut seperti, menjalankan shalat lima waktu, shalat jum'at, shalat teraweh di bulan ramadhan dan juga buka puasa bersama. Di daerah desa tangga batu 1 terdapat empat sekolah tingkat dasar, 3 Sekolah tingkat menengah dan 1 sekolah tingkat atas.

Penduduk Komplek Perumahan PT.BDSN Desa Tangga Batu 1 Kec. Parmaksian Kab. Toba yang mayoritas penduduknya adalah muslim sangat butuh dengan pengajar yang mengajarkan tentang agama yang benar atau seorang da'I yang mana dapat mengajarkan mereka tentang agama islam yang benar serta membantu dalam permasalahan kehidupan sehari hari dengan cara yang disyariatkan Allah serta sesuai dengan apa yang diajarkan Nabi Muhammad Shalallahu 'alaihi Wassalam.

Penduduk Komplek Perumahan PT.BDSN Desa Tangga Batu Kec. Parmaksian Kab. Toba memiliki semangat beragama yang tinggi akan tetapi dengan adanya keterbatasan ilmu dan kesibukan dalam bekerja serta sedikitnya para penceramah, ustadz serta da'I yang menetap menyebabkan kegiatan keagamaan di dalam Komplek menjadi menurun.

Oleh karena itu, sangat penting untuk diadakannya kegiatan Kuliah Kerja Lapangan (KKL) di daerah Komplek Perumahan Desa Tangga Batu 1 Kec. Parmaksian Kab. Toba sebagai sarana untuk menyampaikan islam yang serta menghidupkan lagi kegiatan kegiatan keagamaan yang dapat menjadikan penduduk komplek memiliki pemahaman islam yang benar sesuai dengan apa yang telah diperintah oelh Allah serta yang telah diajarkan oleh Rasul-Nya.

Lantas, bagaimana bentuk kegiatan pengabdian masyarakat yang dilaksanakan oleh mahasiswa STAI As-sunnah di Komplek Perumahan PT. BDSN Desa Tangga Batu 1 Kec. Parmaksian Kab. Toba untuk mengatasi sedikitnya penceramah atau da'I dan membimbing masyarakat dalam menjalani kehidupan beragama? Dan bagaimana dampak kegiatan kegiatan tersebut terhadap kehidupan penduduk Komplek Perumahan PT.BDSN Desa Tangga Batu 1 Kec. Parmaksian Kab. Toba? 
Adapun metode yang digunakan dalam pemecahan permasalahan yang terjadi yaitu melalui kajian deskriptif dan survey. Dengan data kualitatif di Komplek Perumahan PT.BDSN Desa Tangga Batu 1 Kec. Parmaksian Kab. Toba pada tahun 1442H/2021M.

\section{Pembahasan dan Hasil}

Salah satu usaha untuk menyebarkan pemahaman agama islam adalah dengan berdakwah. Secara etimologi dakwah berasal dari Bahasa arab d'a yad;u da'watan yang berarti mengajak atau seruan ${ }^{1}$ atau yang berarti ajakan, seruan, panggilan, atau undangan. ${ }^{2}$ Adapun secara istilah ibnu taimiyah mengartikan dakwah sebagai proses usaha untuk mengajak masyarakat untuk beriman kepada Allah dan Rasul-Nya sekaligus menaaati apa yang diperintahkan oleh Allah dan Rasul-Nya itu ${ }^{3}$. Sementara Abdul Munir Mulkhan mengartikan dakwah sebagai usaha mengubah situasi kepada yang lebih baik dan sempurna, baik terhadap individu maupun masyarakat ${ }^{4}$. Sedangkan Syeikh Ali Mahfudz dalam kitabnya "Hidayatul Mursyidin" mengatakan bhwa dakwah adalah mendorong manusia untuk berbuat kebajikan dan mengikuti petunjuk (agama), menyeru mereka pada kebaikan dan mencegahh mereka dari perbuatan mungkar agar mereka memperoleh kebahagiaan dunia

Allah berfirman:

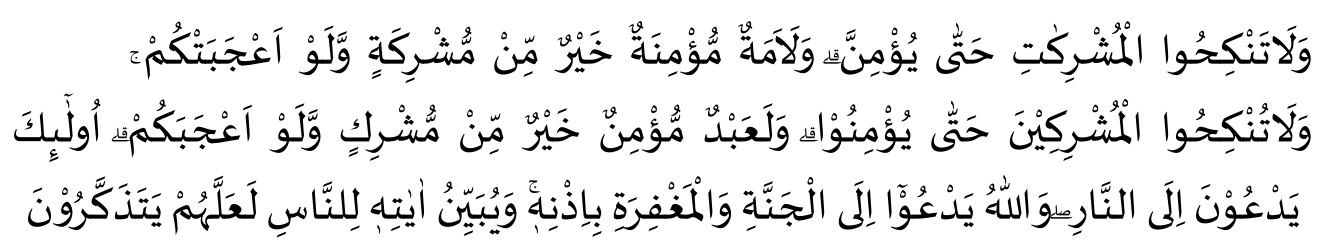

"Dan janganlah kamu nikahi perempuan musyrik, sebelum mereka beriman. Sungguh, hamba sahaya perempuan yang beriman lebih baik daripada perempuan musyrik meskipun dia menarik hatimu. Dan janganlah kamu nikabkan orang (laki-laki) musyrik (dengan perempuan yang beriman) sebelum mereka beriman. Sungguh, hamba sabaya lakilaki yang beriman lebih baik daripada laki-laki musyrik meskipun dia menarik batimu. Mereka mengajak ke neraka, sedangkan Allab mengajak ke surga dan ampunan dengan

${ }^{1}$ Rosidah,"Definisi Dakwah Islamiyah ditinjau dari Perspektif Konsep Komunikasi Konvergensi dan Katherine Miller", dalam JURNAL QATHRUNA, vol.2, no.2, juli-desember, 2015, hal. 159

2Kumalasari, Bela, "Pengertian Dakwah",2019, hal.1

${ }^{3}$ Farihah, Irzum,"Pengembangan Karier Pustakawan Melalui Jabatan Fungsional Perpustakaan Sebagai Media Dakwah", dalam Rumah Jurnal IAIN Kudus, vol. 2, no.1, Januari-Juni, 2014, hal. 121

${ }^{4}$ Ibid, hal.121

${ }^{5}$ Mohammad Hassan, O.Cit.h.19.

Jurnal WARAQAT • Volume VI, No. 1, Januari-Juni 2021 |90 
iæin-Nya. (Allab) menerangkan ayat-ayat-Nya kepada manusia agar mereka mengambil pelajaran ${ }^{6}$.

Sulthon memberikan klarifikasi pemahaman pakar Islam mengenai dakwah yaitu: pertama, dakwah adalah usaha yang mengarah untuk memperbaiki suasana kehidupan yang leboh baik dan layak sesuai dengan kehendak dan tuntutan yang benar, kedua, Dakwah adalah usaha membuka konfrontasi keyakinan ditengah manusia, membuka kemungkinan bagi kemanusiaan untuk menetapkan pilihannya sendiri, ketiga, Dakwah islam adalah dakwah kepada standar nilai-nilai kemanusiaan dalam tingkah laku pribadi-pribadi didalam hubungan antar manusia dan sikap perilaku antar manusia, keempat, Dakwah adalah mengajak manusia dengan cara bijaksana kepada jalan yang benar sesuai dengan perintah tuhan untuk kemaslahatan dan kebahagiaan mereka didunia dan akhirat. Kelima, Dakwah merupakan suatu proses usaha untuk mengajak agar orang beriman kepada Allah, percaya dan mentaati apa yang telah diberitakan Rosul serta mengajak agar dalam menyembah kepada Allah seakan-akan melihatnya, keenam, Dakwah adalah usaha mengubah situasi kepada yang lebih baik dan sempurna, baik terhadap individu maupun masyarakat, ketujuh, Dakwah adalah gerakan untuk merealisasikan undang-undang (ihya al-nidham) Allah yang telah menurunkan kepada nabi Muhammad SAW, kedelapan, Dakwah adalah mendorong (memotidasi) Ummat manusia agar melaksanakan kebbaikan dan mengikuti petunjuk serta memerintah berbuat ma'ruf dan mencegah dari perbuatan mungkar supaya mereka memperoleh kebahagiaan dunia akhirat. Dan kesemnilan, dakwah adalah setiap usaha atau aktifitas dengan lisan atau tulisan dan lainya yang bersifat menyeru, mengajak, memanggil manusia lainya untuk beriman dan menaati Allah ta'ala sesuai dengan garis- garis aqidah dan Syariah serta Akhlaq Islamiyah. ${ }^{7}$

Dari pemaparan diatas dapat disimpulkan bahwa dakwah adalah segala yang berbentuk penyampaian, ajakan, seruan kepada masyarakat dalam luanglingkup agama islam dengan cara yang baik dan bijaksana yang dapat meningkatkan keinginan masyarakat dalam memahami agama islam pada seluruh aspek kehidupan.

Allah telah memerintahkan hambanya untuk berdakwah, karna dengan bedakwah lah agama islam ini dapat tersampaikan kepada masyarakat lainya dan dengan dakwah inilah islma dapat bangkit menjadi suatu agama yang kuat dan apabila dakwah ini tidak ada dunia ini akan dipenuhi oleh kebodohan akan ilmu serta buta terhadap agama islam dan masyarakat akan menjadi semakin jauh dari islam. Diantara ayat ayat yang menunjukkan kewajiban untuk berdakwah adalah:

\footnotetext{
${ }^{6}$ Alquran Surah Albaqarah [2]: 221

${ }^{7}$ Farihah, Irzum," Pengembangan Karier Pustakawan Melalui Jabatan Fungsional Perpustakaan Sebagai Media Dakwab”, dalam Rumah Jurnal IAIN Kudus, vol. 2, no.1, Januari-Juni, 2014, h. 121
} 
Allah ta'ala berfirman:

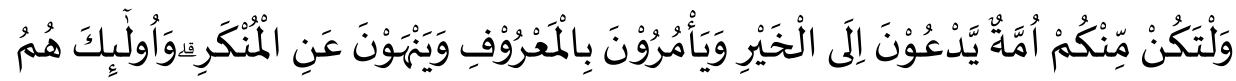
الملْفِلِحُوْنَنَ

"Dan hendaklah ada di antara kamu segolongan umat yang menyeru kepada kebajikan, menyuruh kepada yang makruf dan mencegah dari yang munkar, merekalah orang-orang yang beruntung."

Allah berfirman:

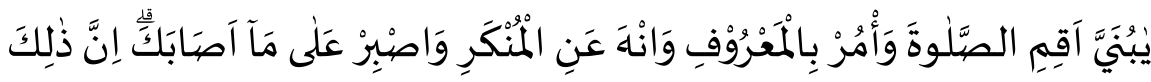 مِنْ عَزْمِ الْلْمُوْرِ}

"Dan surublah (manusia) mengerjakan yang baik dan cegablah (mereka) dari perbuatan yang mungkar dan bersabarlah terhadap apa yang menimpa kamu. Sesunggubnya yang demikian itu termasuk hal-hal yang diwajibkan (oleh Allah)."

Dalam ayat lainya Allah berfirman:

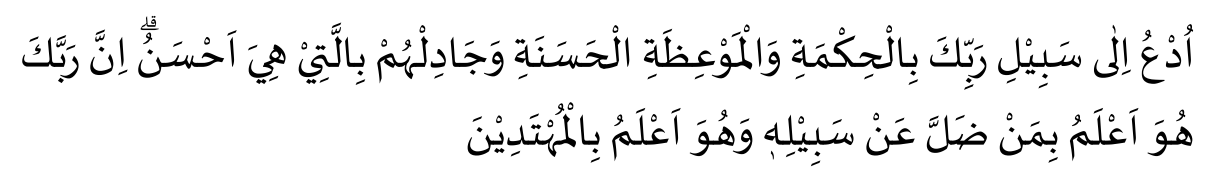

"Serulah manusia kepada jalam Tuhanmu dengan bikmah dan pelajaran yang baik dan bantablah mereka dengan cara yang baik, sesunggubnya Tuhanmu Dialah yang lebih mengetahui tentang siapa yang tersesat dari jalan-Nya dan Dialah yang lebih mengetabui orang-orang yang mendapat petunjuk."

Adapun dalil- dalil yang berasal dari nabi Muhammad Shalallahu 'alaihi wasalam diantaranya:

Hadis Nabi yang diriwayatkan dari Abu Said Al Khudri:

${ }^{8}$ Alquran Surah Al Imran [3]: 104

${ }^{9} \mathrm{Al}$ Quran Surah Luqman [31]:17

Jurnal WARAQAT • Volume VI, No. 1, Januari-Juni 2021 | 92 


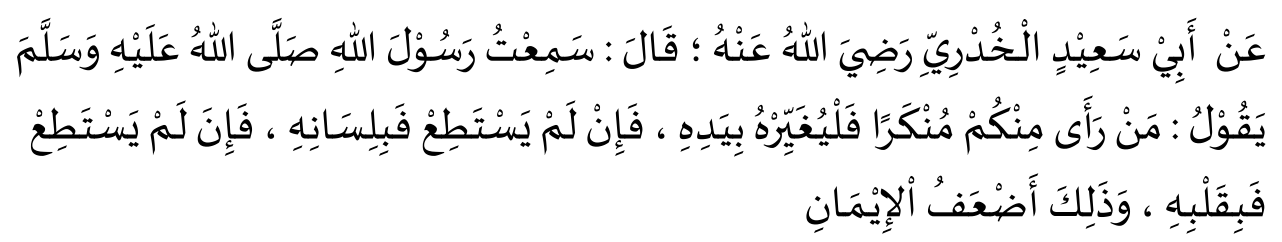

"Dari Abu Sa'乞̂d al-Khudri Radhiyallabu anhu, ia berkata, "Aku pernah mendengar Rasûlullâh Shallallahu 'alaibi wa sallam bersabda, Barangsiapa di antara kalian melihat kemungkaran, maka hendaklah ia mengubahnya dengan tangannya (kekuasaannya); jike ia tidak mampu, maka dengan lidahnya (menasibatinya); dan jika ia tidak mampu juga, maka dengan hatinya (merasa tidak senang dan tidak setuju), dan demikian itu adalah selemah-lemah iman. ${ }^{10}$

Adapun hakikat dari dakwah adalah: 1) at-taujih adalah memberikan tuntunan dan pedoman serta jalan hidup mana yang harus dilalui oleh manusia dan jalan mana yang harus dihindari, sehingga nyatalah jalan hidayah dan jalan yang sesat. 2) at-taghyir yaitu mengubah dan memperbaiki keadaan seseorang atau masyarakat kepada suasana hidup baru yang didasarkan pada nila-nilai Islam. 3) at-tabsyir adalah memberikan harapan akan sesuatu nilai agama yang disampaikan. Dalam hal ini dakwah harus mampu menunjukkan nilai apa yang terkandung didalam suatu perintah agama, sehingga dirasakan sebagai kebutuhan vital dalam kehidupan masyarakat ${ }^{11}$.

Kegiatan pengabdian masyarakat atau Kuliah Kerja Lapanagan (KKL) yang dilaksanakan oleh mahasiswa/i STAI As-sunnah di Komplek Perum PT.BDSN Desa Tangga Batu 1 Kec. Parmaksian Kab. Toba diantaranya untuk mendakwahi masyarakat, mengajarkan tentang islam, mengajarkan anak anak dalam membaca al quran dan membuat acara-acara keagamaan untuk meningkatkan semangat beragama berlangsung baik. Kegiatan ini melibatkan Dewan Kepengurusan Masjid (DKM) Komplek Perum PT.BDSN dalam pelaksanaanya. Adapun dampak dari kegiatan kegiatan tersebut sangat positif, terlihat dari antusias masyarakat, mulai dari datangnya orang-orang ke masjid untuk mneghadiri acara keagamaan, adanya orang-orang yang bertanya tentang hal-hal keagamaan seperti fiqih,muamalat bagaimana cara ber-khatib serta menanyakan tentang masalah aqidah dan tauhid. Antusias juga terlihat dari kalangan anak-anak yang semagat dalam mempelajari Al Quran dan dasar dasar islam, mereka datang ketempat pembelajaran lebih cepat dari waktu yang ditentukan, mengajak teman-temannya yang awalnya hanya 20 orang menjadi 35 orang dan terus bertambah hingga pada akhir acara ada sekita 50 anak muslim yang mengikuti kegiatan keagamaan yang diadakan. Selain itu masyarakat juga gemar mengadakan buka bersama di masjid dengan masyarakat setempat dan

${ }^{10}$ Hadis Amar Makruf Nahi Mungkar. HR. Muslim. Dorar.net.

${ }^{11}$ Baiti Renel, Tesis: Materi Dakwah Dan Kebutuban Mad'u, (Makassar, 2012), hal. 30. 
juga bersama para karyawan peruhaan lain seperti karyawan PT.PLN, PJBS dan lainya.

\section{Penutup}

Penduduk Komplek Perumahan PT BDSN Desa Tangga Batu 1 Kec. Parmaksian Kab. Toba adalah penduduk yang mayoritas Islam dan berdomisili di luar pulau Sumatra. Masjid Al Ikhlas adalah Masjid dimana dilakukannya kegiatan Kuliah Kerja Lapangan (KKL) oleh mahasiswa STAI As-sunnah. masyarakat setempat sangat mendukung dengan adanya kegiatan KKL ini, terlihat dari antusias para penduduk mereka sangat aktif dalam kegiatan-kegiatan yang diadakan oleh mahasiswa STAI As-sunnah begitu pula di kalangan anakanak tidak kalah antusias dengan kalangan orang dewasa, mereka selalu semangat ketika belajar AlQuran dan dasar-dasar agama Islam bersama-sama.

Kegiatan KKL oleh mahasiswa STAI As-sunnah ini berfokus kepada pendidikan agama islam dasar untuk kehidupan sehari-hari dan pendidikan Al Quran bagi anak-anak yang mana bertujuan agar para penduduk setempat dapat mengaplikasikan syariat islma dalam kehidupan sehari-hari serta membina dan mendidik anak-anak sebagai calon penerus bangsa dan penegak agama islam.

Kegiatan KKL oleh mahasiswa STAI As-sunnah ke Komplek Perumahan PT BDSN Desa Tangga Batu 1 Kec. Parmaksian Kab. Toba ini telah berlangsung sejak 4 tahun lalu, akan tetapi kegiatan ini berhenti sejak adanya wabah Covid-19 karna adanya peraturan Lock Down oleh pemerintah. Pada tahun ini peraturan daerah telah membolehkan adanya kegiatan antar daerah dengan itu STAI As-sunnah mengadakan kegiatan KKL dan mengutus mahasiswanya ke Komplek Perum PT BDSN untuk mendakwahi agama islam dan mengisi acara -acara keagamaan lagi dan mengajarkan islam disana.

Saran, Kegiatan Kuliah Kerja Lapangan (KKL) mahasiswa STAI Assunnah diadakan sekitar 2 pekan, sejak 5 - 21 Ramadhan $1442 \mathrm{H}$ atau 17 April s/d 3 mei 2021 M, merupakan waktu yang sangat singkat untuk menyebarkan agama islam yang benar. Tetapi keinginan masyarakat akan kegiatan ini sangatlah besar, mereka ingin adanya da'I yang mengajarkan islam yang benar disana yang mana dapat membantu mereka dalam menyelesaikan permasalahan sehari hari sesuai dengan syariat yang telah diperintahkan Allah Subhanahu wa ta'ala.

Oleh karna itu kami menyarankan agar kegiatan KKL ini diberi waktu lebih agar apa yang disampaikan di masyarakat dapat lebih banyak dan masyarkat lebih mengenal islam dengan baik serta kegiatan ini juga dapat meningkatkan atau mengisi ulang semangat beragama di masysarakat, sehingga penyebaran agama islam dapat berjalan dengan baik dan menimbulkan hasil yang baik agar terciptanya dunia indah yang berjalan sesuai dengan aturan Allah Ta'ala. 


\section{Referensi}

Alquran Alkarim

Hadis.Dorar.net

Renel, Baiti. Tesis: Materi Dakwah Dan Kebutuban Mad'u. Makassar. 2012.

Rosidah,"Definisi Dakwah Islamiyah ditinjau dari Perspektif Konsep Komunikasi Konvergensi dan Katherine Miller", JURNAL QATHRUNA, 2015.

Kumalasari, Bela, "Pengertian Dakwah": Surabaya, 2019.

Farihah,Irzum," Pengembangan Karier Pustakawan Melalui Jabatan Fungsional Perpustakaan Sebagai Media Dakwah", Rumah Jurnal IAIN Kudus, : 2014. 